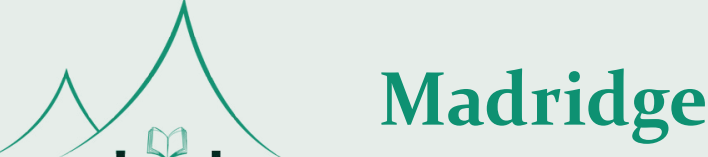 \\ madridge Journal of AIDS \\ interconne
}

Commentary Article

Open Access

\section{Can the Criminal Justice System Offer Public Health Alternatives to Persons with HIV in the Criminal Justice System?}

\author{
David LaBahn and Erica McWhorter* \\ Association of Prosecuting Attorneys, 1615 L Street, NW, Suite 1100, Washington, DC 20036, USA
}

\section{Article Info}

\section{*Corresponding author: \\ Erica McWhorter \\ Deputy General Counsel \\ Association of Prosecuting Attorneys \\ 1615 L Street, NW, Suite 1100, Washington \\ DC 20036, USA \\ E-mail: erica.mcwhorter@apainc.org}

Received: August 15, 2015

Accepted: September 23, 2015

Published: September 24, 2015

Citation: LaBahn D, McWhorter E. Can the Criminal Justice System Offer Public Health Alternatives to Persons with HIV in the Criminal Justice System? Madridge J AIDS. 2015; 1(1): 9-11.

doi: 10.18689/mja-1000102

Copyright: $\odot 2015$ The Author(s). This work is licensed under a Creative Commons Attribution 4.0 International License, which permits unrestricted use, distribution, and reproduction in any medium, provided the original work is properly cited.

Published by Madridge Publishers

\begin{abstract}
This commentary will address how prosecutors can use existing legislation, innovative court-related programs, and smart prosecution techniques to fulfill their duty to protect public safety as it relates to persons with HIV in the criminal justice system. This will be accomplished in part by examining the prosecutors' role and their responsibility to ensure public safety as it relates to public health issues raised by HIV persons entering and exiting the criminal justice system. While prosecutors have some discretion as it pertains to charging decisions and diversion options, they are duty-bound to follow the law. Therefore, it is imperative that the law keep up with medical progress. Finally, the commentary will examine how court-related programs directed at public health and safety issues may be useful tools to positively impact the immediate and ongoing treatment needs of HIV positive persons in the criminal justice system, specifically those persons involved in the system due to narcotics. Although these alternative programs typically provide services to substance abusers and persons with mental health problems, other public health and safety issues have been addressed in many jurisdictions nationwide using those or similar modalities.
\end{abstract}

Keywords: Criminal Justice System; Public Health; Legislation; HIV.

Abbreviations: APA: Association of Prosecuting Attorneys; CDC: Center for Disease Control; DOJ: Department of Justice's; ACA: Affordable Care Act.

\section{Introduction}

The Association of Prosecuting Attorneys (APA) supports prosecutors nationwide, including prosecutors in 30 of the largest jurisdictions in the United States. APA's mission is to support and enhance the effectiveness of prosecutors in their efforts to help make our communities safer. One method of the support APA provides is technical assistance and training to prosecutors across the country on the development and implementation of innovative practices and alternative courts and programs, which are used to divert people from the criminal justice system and provide treatment while addressing the person's criminal conduct.

Prosecutors nationwide have a responsibility to promote public safety in their decisions. Additionally, prosecutors across the nation have been increasingly willing to support criminal justice reform in the form of diversion programs and other innovative practices. Since public health can implicate issues of public safety, it may be possible that both issues can be addressed using those tools and practices. While prosecutors have "prosecutorial discretion," this does not mean they can merely choose when and how to apply the law. Instead, 
prosecutorial discretion is about following the applicable statutes so that the outcome is in the interest of justice. Prosecutors are just one of several criminal justice stakeholders. Therefore, the use of their discretion can play a role in whether a certain program or practice can be used to assist HIV positive persons who are already involved in the criminal justice system to receive continued HIV treatment, while also addressing the reasons they became involved in the system. This is often effectuated by the prosecutor and other stakeholders supporting the use of alternative courts or programs (like gateway or reentry programs) that may provide stabilizing and treatment services to the person involved in the system.

\section{Commentary}

HIV is a physical and public health issue. It is communicable yet treatable. However, there are approximately 50,000 new HIV infections per year [1]. While the number of new HIV infections remains stable, the pace of new infections among certain groups, including injection drug users, continues at a higher level than other groups [2]. As of July 2015, the Center for Disease Control (CDC) found that between 2010 and 2011 injection drug users rate of infection almost doubled. Although HIV is primarily thought of as a public health concern, if is untreated it can become a public safety issue. For example, in 2015 the Indiana State Department of Health released a public statement announcing that there was a "quickly spreading outbreak of HIV" where "the majority of cases" were linked to "injection drug abuse" [2]. Four months later the Indiana State Department of Health announced that the outbreak had increased despite the state, local and federally-sponsored needle exchange program response [3]. Similarly, in 2010 the Colorado Department of Public Health and Environment released an integrated epidemiological profile of HIV. That study found that rural and frontier counties faced the highest number of injection drug users, which accounted for over $18 \%$ of all HIV cases in Colorado in 2010 [4].

In 1990 the federally enacted Ryan White CARE Act, financially incentivized states to create HIV treatment and prevention programs if they passed laws imposing criminal penalties on persons intentionally transmitting HIV and other sexually transmitted diseases [5]. The goal was to promote public health. While studies of the laws of various states show a rise in those laws, the majority of persons in contact with the criminal justice system are involved due to other criminal activity, including prostitution and the possession and distribution of narcotics [6].

In response to the HIV epidemic and the increasing number of laws penalizing certain activities (including prostitution and needle sharing for use in injecting narcotics by persons with HIV) in 2015 the White House issued the 2020 national HIV/AIDS Strategy with input from APA [7]. That strategy described the United States Department of Justice's (DOJ) collaboration with the CDC, which examined state criminal laws and produced "a best practices guide to reform criminal laws and help states ensure their policies do not place unnecessary burdens on individuals living with AIDS" [7]. This guide also encourages state criminal statutes to reflect a current accurate understanding of HIV transmission and associated treatment [7].

The CDC cites several factors that pose HIV prevention challenges, including substance abuse, mental illness, physical health-related stigmas, and socioeconomic issues [7]. Throughout the US, methods of dealing with these factors once a person is involved in the criminal justice system have been successfully created. Prosecutors nationwide have been proponents of such systems. Prosecutors have been specifically supportive of the systems that treat some of those issues as part of their rehabilitation programs. These options may be good alternative health treatment systems for HIV positive persons involved in the criminal justice system, as well as a starting point for evidence-based prevention and treatment measures. However, to date, many of those systems do not address issues of physical health very well, despite the impact that physical health has on substance abusers and persons with mental health disorders-the most common participants in those systems.

The use of alternative courts and diversion programs for the purpose of promoting the treatment and prevention of infectious disease transmission encourages those courts and programs to take a holistic approach to treatment and the issues that contribute to the participants' criminal behavior. While those systems may be possible options to fill the gap between rehabilitation for criminal offenses and the treatment and prevention of infectious diseases, three considerations should be noted as to whether those systems, including the most common system (drug treatment courts), can be expanded to include treatment for physical health issues-like HIV positive persons who are injection drug users. The first consideration being whether drug courts should address every issue related to the person involved in the criminal justice system in order to effectuate a rehabilitated person who is unlikely to reenter the criminal justice system again. The second consideration is that there are huge variables in size, scope, and resources of the jurisdictions and systems, which justifiably question the capacity of those systems to address such extensive health concerns. A third consideration relates to what a system would require of prosecutors. For instance, if systems are unable to address the physical health issues (like HIV) of participants already involved in the criminal justice system, then that gap in physical health treatment of participants can pose additional public safety problems beyond the reasons for which the participant initially entered the criminal justice system. Those public safety issues then trigger the response of prosecutors.

In addition, health workers, the courts, and their stakeholders, including prosecutors, should look to the Affordable Care Act (ACA) for further options to address the health needs of HIV infected persons. Using the ACA to fill the treatment and prevention gap in the criminal justice system (and elsewhere) will be a work in progress as the ACA is new and has relatively few structures in place to provide such resources to populations like HIV positive injection drug users. 
Therefore, gaps still and may continue to exist in the treatment of HIV infected drug users, regardless of their status in the criminal justice system or its related rehabilitation programs.

\section{Where Does This Leave Us?}

Prosecutors have several roles that they must fill in the criminal justice system in order to fulfill their primary mission of enhancing public safety. First, they are responsible for ensuring accountability of persons who are suspected of breaking the law. This is a victim-centered assessment of whether the person committed the crime, whether law enforcement can prove that, and whether the jurisdiction should charge the person. Second, prosecutors are responsible on behalf of the jurisdiction for making the decision as to whether to charge the person. This decision is based on what the disposition of the case will look like, specifically what is the right thing to do in the situation. This decision will be influenced by both the law of the jurisdiction and the prosecutor's discretion within the confines of the law. This means that prosecutors make decisions that follow the applicable statutes so that the outcome is in the interest of justice. More and more frequently, with certain cases, specifically those involving substance abuse, the prosecutor has the option to consider how best to promote public health, and therefore public safety. Due to the impressive availability of alternative courts and treatment programs, prosecutors can promote public safety by supporting efforts to obtain and maintain treatment for the person who is to be or has been charged. That can be done through the person's participation in one of those systems. Persons who are HIV positive and fit into an applicable category of available court-related alternative programs can benefit greatly from this use of discretion.

\section{Conclusion}

Prosecutors are in a unique position to assist in addressing the issue of HIV persons involved in the criminal justice system by participating as necessary stakeholders in the formation and implementation of alternative courts and diversion programs. While public health is not always fully addressed in those systems, the possibility is there. Notably, prosecutors have and continue to encourage the use of those systems as they enhance the prosecutors' ability to promote communityoriented public safety. Although prosecutors cannot bear this burden alone, it is significant that many prosecutors in the United States have already begun developing and supporting a wide range of alternative courts and diversion programs that can be expanded to include a broad holistic response to persons involved in the criminal justice system. Being mindful of the considerations previously discussed, prosecutors can and should remain active in efforts like those described to enhance public safety, especially when those efforts involve vulnerable members of the community (like HIV positive injection drug users) and possible negative public health consequences as they relate to public safety.
Conflicts of Interest: The authors declare no conflict of interest with this submission.

\section{Acknowledgments}

Great thanks to Carolyn Hardin and Carson Fox, Jr. of the National Association of Drug Court Professionals for their time and insight in developing some of the themes within this article and connecting us to reliable sources. Special thanks also to Lloyd Gold Samt for his patient, thorough, and insightful provision of policy considerations related to HIV issues and the possibility of programmatic court intervention.

\section{References}

1. Center for Disease Control. HIV among Pregnant Women, Infants and Children in the United States. Accessed 2015.

2. Center for Disease Control. HIV in the United States: At a Glance. Accessed 2015.

3. Indiana State Department of Health. Immediate Release: HIV Outbreak in Southeastern Indiana. Accessed 2015.

4. Colorado Department of Public Health and Environment. Integrated Epidemiological Profile of HIV and AIDS Prevention and Care Planning reported through December 2010. Accessed 2015.

5. Kemp DS. The Failure of Criminal HIV Transmission Laws. Accessed 2015.

6. Center for Disease Control. HIV-Specific Criminal Laws. Accessed 2015.

7. Office of National AIDS Policy. National HIV/AIDS Strategy for the United States 2020. Accessed 2015. 